\title{
Le guide esthétique \\ Comment réussir le sourire de vos patients
}

Authors: Jean-Christophe Paris / André-

Jean Faucher

Publisher: Quintessence International

Language: French

ISSN: 978-2-91255-023-1

Edition: $1 / \mathrm{e}$

Publish Year: 2004

Pages: 309

Price: $€ 181.00$

The book Le Guide Esthetique (The Aesthetic Guide) presents the joint effort of educators and practitioners to answer a fundamental question of dental aesthetics, namely "how we can improve the patient's smile."

The authors propose an original analysis of the criteria that influence the success of an aesthetic treatment.

The book is divided into seven chapters eloquently and amply illustrated. After a psychological approach to aesthetics, the authors go to its visual perception, the fundamental rules of aesthetics and beauty canons, which are amply described. The macrophotography and photographic materials needed as well as the protocol are presented in a

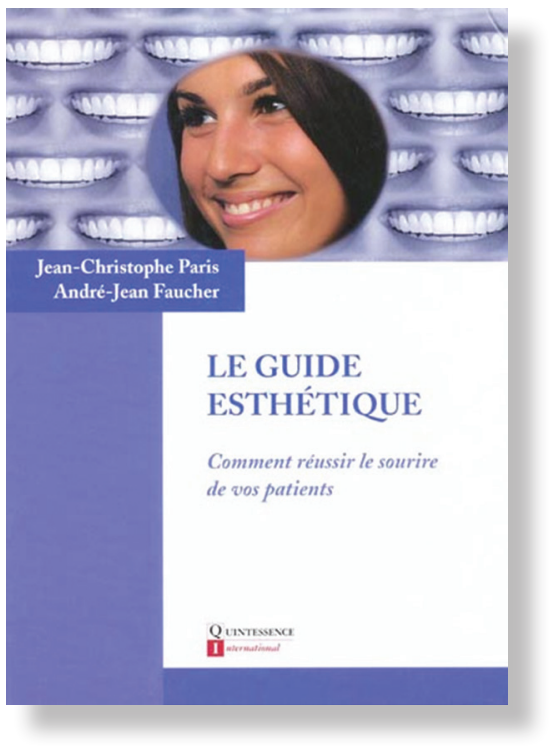

separate chapter.

The last two chapters develop a detailed aesthetic guide which is illustrated by a series of clinical cases.

The book is accompanied by a booklet summarizing the authors' major principles and is a pedagogical and methodological support for any practitioner who wants to add a new side to his practice.

https://doi.org/10.25241/stomaeduj.2016.3(1-2).bookreview.4

Florin Eugen Constantinescu,DDS, PhD Student

ROPOSTURO-HolisticDental Medicine Institute, Bucharest, Romania

email: drfflorin.constantinescu@gmail.com

The Book Review is drafted in the reviwer's sole wording and illustrates his opinions. 